\title{
ABORDAGENS PSICOLOGICAS DO DESENVOLVIMENTO NA PERSPECTIVA DE PIAGET, WALLON E VYGOTSKY E SUAS IMPLICAÇÕES NA PRÁTICA PEDAGÓGICA
}

\begin{abstract}
César Augusto de Jesus França ${ }^{1}$ Antonia Dalva França-Carvalho

INTRODUÇÃO: Este trabalho propôs a exposição de forma sucinta de três correntes da psicologia do desenvolvimento e da aprendizagem: Abordagem Piagetiana; Psicogenética de Wallon e Abordagem Sócio-cultural de Vygotsky, suas bases epistemológicas, conceitos básicos e implicações pedagógicas, os quais descrevem e explicam os processos de desenvolvimento e aprendizagem, bem como, a importância da psicologia na formação do educador.
\end{abstract}

METODOLOGIA: Em razão de buscar informações específicas a pesquisa constituiu-se através de método e técnica específico de trabalho analítico e reflexivo. Utilizou-se como método a consulta bibliográfica de autores e trabalhos no campo da psicologia e psicologia da educação. Dispôs-se da abordagem qualitativa para a análise e apresentação das informações coletadas das fontes, na perspectiva de ampliam o campo de compreensão desta proposta.

RESULTADOS: Com a pesquisa e posterior análise das informações a respeito da psicologia da educação, seus principais pressupostos teóricos e sua aplicação na prática pedagógica. Tem-se a compreensão da dimensão e da necessidade das contribuições que os autores e suas teorias no campo do desenvolvimento e aprendizagem propõem.

A psicologia como ciência, ou as psicologias com suas abordagens, buscam o estudo da complexidade dos fenômenos que permeiam o homem em todas as suas dimensões. Entendendo este homem como um ser biopsicossocial, determinado também pelas condições históricas e sociais que o cercam. Através dos seus métodos e técnicas busca compreender os fenômenos psíquicos e intervir nos casos onde haja sofrimento psíquico humano, visando a homeostase mental, emocional, físico e social e outros.

A psicologia educacional ou da educação como subcampo da psicologia, busca a investigação dos fenômenos e aplicabilidade de técnicas e princípios da psicologia científica ao campo da educação.

\footnotetext{
${ }^{1}$ Graduando de licenciatura em História. Bolsista OBEDUC/UFPI/CAPES.

${ }^{2}$ Coordenadora Institucional do OBEDUC/UFPI/CAPES. E-mail: adalvac@uol.com.br
} 
Dessa forma as contribuições de Piaget para a compreensão do desenvolvimento da estrutura cognitiva das crianças, ao considerar a infância um período com particularidades na formação do pensamento, e tal pensamento chega a se completar na fase adulta, descrevendo descreveu o conceito de assimilação, acomodação e equilibração.

Com a concepção de estágios do desenvolvimento cognitivo bem definido: o período sensório-motor, período pré-operatório, período das operações concretas e período das operações formais, onde surgem novas formas de organização mental, onde em cada estágio a criança pensa e age de uma forma.

Conceitos fundamentais para a organização etária nas escolas e no caso do professor na compreensão da importância da existência de esquemas - ponto de partida para o conhecimento - para a aprendizagem.

A teoria de Wallon aplicada à educação, a psicogenética propõe que o ser humano é organicamente social, assim em cada indivíduo o desenvolvimento orgânico necessita da influência da cultura para se atualizar. Wallon dar ênfase na análise genética, a qual considera a única forma de manter a totalidade do objeto pesquisado.

Dessa forma essa nova ciência se propõe a estudar profundamente fenômenos humanos como: movimento, emoção, inteligência e personalidade e veremos como isso se aplica a pedagogia. A dimensão afetiva na psicogenética de Wallon ocupa lugar central na construção do indivíduo e do conhecimento. Propôs os estágios do desenvolvimento humano, como um processo contínuo: estágio impulsivo emocional ( 0 a 1 ano); estágio sensório motor e projetivo (1 a 3 anos); estágio personalismo ( 3 a 6/7 anos); estágio categorial ( 7 a 11 anos) e estágio da adolescência (12 a 18 anos).

Sua importância para a educação é lembrar aos professores que devem ter uma compreensão totalizante (consciência, eu, emoções, representações̃, etc.), do educando.

A abordagem histórico-cultural de Vygotsky propõe que o desenvolvimento intelectual, principalmente das crianças, ocorre em função das interações sociais e condições de vida, ou seja, o meio onde os processos psicológicos individuais são transformados em processos históricos complexos. Assim sujeito interage com o meio cultural em que vive, mediado por um sujeito mais experiente, onde este propicia ao outro sujeito um desenvolvimento real antes precedido de um desenvolvimento proximal, que leva novamente a um desenvolvimento real, num processo continuo de aprendizado e desenvolvimento cognitivo. Destaca a linguagem como tendo o papel de sistema complexo de signos mais importante para o homem.

A abordagem histórico-cultural traz à luz a perspectiva que, educação e aprendizado na escola são intencionais e planejadas sistematicamente dentro de critérios científicos. Porém, a 
instituição Escola deverá fornecer condições para o professor/mediador e o aluno/ativo no processo histórico da sociedade em que vivem juntos, aprenderem novos significados, novos modos de agir, de elaborar e compartilhar conhecimento.

CONSIDERAÇÕES FINAIS: O presente trabalho expôs de forma sucinta a importância e contribuição da psicologia enquanto ciência para a compreensão dos fenômenos psíquicos que envolvem os sujeitos implicados no processo de ensino e aprendizagem. As três correntes da psicologia do desenvolvimento e da aprendizagem: Abordagem Piagetiana; Psicogenética de Wallon e Abordagem Sócio-cultural de Vygotsky, suas bases epistemológicas, conceitos básicos e implicações pedagógicas, os quais descrevem e buscam explicar os processos de desenvolvimento e aprendizagem para uma melhor prática pedagógica.

\section{APOIO: OBEDUC/CAPES/UFPI}

\section{REFERÊNCIAS}

BRAGUIROLLI, Elaine Maria. Psicologia Geral, São Paulo: Editora Vozes, 2004.

COUTINHO, M. T. da C; MOREIRA, M. Psicologia da Educação: um estudo dos processos psicológicos de desenvolvimento e aprendizagem humanos, voltados para educação - ênfase nas abordagens interacionistas do psiquismo humano, São Paulo: Editora Lê 1995.

DENER, Luiz da Silva; Do Gesto ao Símbolo: a teoria de Henri Wallon sobre a formação simbólica. 2007. $15 \mathrm{p}$.

Disponível em $<$ http://www.scielo.br/scielo.php?script=sci_arttext\&pid=S0104-40602007000200010 $>$. Acesso em: 08 agostos. 2014. FONTANA, R; CRUZ, M. N. Psicologia e Trabalho Pedagógico, São Paulo: Atual, 1997. OLIVEIRA, M. K. ; DANTA, H. Piaget. Vygotsky. Wallon: Teorias Psicogenéticas em Discussão. São Paulo: Summus, 1992. 